\title{
Remodeling the mitral valve: An outside-in strategy
}

\author{
Laura L. Hocum Stone, $\mathrm{PhD}$, and Rosemary F. Kelly, MD
}

From the Department of Surgery, University of Minnesota, Minneapolis, Minn.

Disclosures: Authors have nothing to disclose with regard to commercial support.

Received for publication Nov 20, 2017; accepted for publication Dec 4, 2017; available ahead of print Jan 23, 2018.

Address for reprints: Rosemary F. Kelly, MD, Department of Surgery, University of Minnesota, 420 Delaware St

SE, Minneapolis, MN 55455 (E-mail: kelly071@umn.edu).

J Thorac Cardiovasc Surg 2018;155:1494-5

$0022-5223 / \$ 36.00$

Copyright $\subset 2017$ by The American Association for Thoracic Surgery

https://doi.org/10.1016/j.jtcvs.2017.12.022

In this issue of the Journal, Kataoka and colleages ${ }^{1}$ present an interesting study that evaluates the efficacy of an externally placed device on experimentally induced ischemic mitral valve regurgitation (IMR). Using a sheep model, they study a surgically positioned, polymer-filled mesh placed externally at the area of posterolateral myocardial infarction. This biocompatible device stabilizes the left ventricle wall, reduces atrial and ventricular remodeling, and reduces chordal tethering without cardiopulmonary bypass. Transthoracic echocardiography and direct pressure measurements demonstrate improved hemodynamic parameters and reduced chordal length, which restores mitral valve function. This innovative device is an alternative solution to mitral valve ring annuloplasty for IMR.

Ventricular restoration for ischemic cardiomyopathy remains an attractive target of therapy. For heart failure, surgical techniques, such as partial left ventriculectomy, and external compression devices, such as CorCap (Acorn Cardiovascular Inc, St Paul, Minn) and HeartNet (Paracor Medical Inc, Sunnyvale, Calif), have been applied to prevent left ventricular (LV) dilatation that occurs in cardiomyopathies. Unfortunately, these approaches fail to normalize LV function or improve survival despite hemodynamic and qualityof-life improvements. ${ }^{2-4}$ Similarly, for IMR, several surgical techniques and devices have been proposed that involve direct repositioning of the papillary muscles, compression of the $\mathrm{LV}$, imbrication of the papillary muscle, or chordal cutting. 5 The complexity of IMR remains challenging, with limited long-term benefits from these options.

Kataoka and colleagues highlight a new technology that targets the specific area of ischemic LV injury and resultant valve dysfunction. IMR affects millions of patients and is associated with a doubling in mortality among patients with mild or greater degrees of regurgitation. ${ }^{7} \mathrm{LV}$ remodeling associated with IMR is dynamic, as location and degree of myocardial injury rather than valve pathology are critical. LV remodeling after ischemic events results in continuous ventricular and atrial chamber enlargement with contractile dysfunction. Repair of IMR with ring annuloplasty is often selected over replacement based on

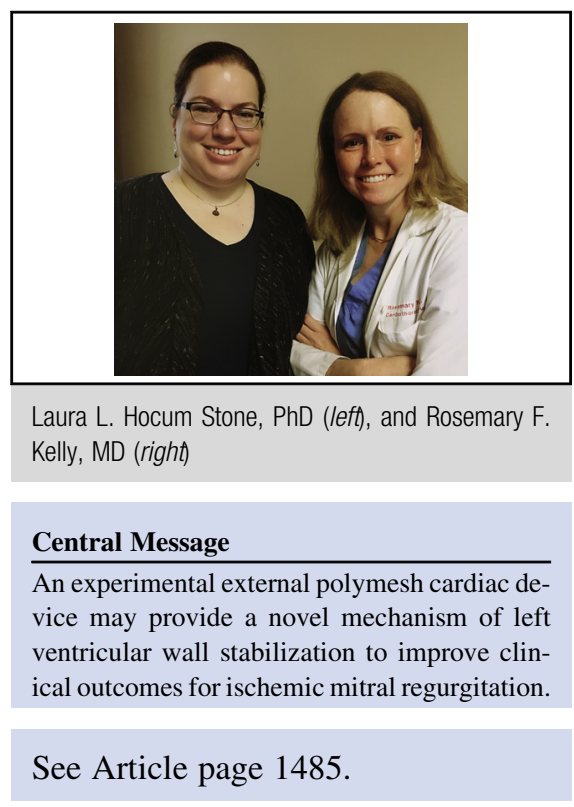

perceptions of improved outcomes with repair and elimination of long-term anticoagulation. ${ }^{8}$ However, a randomized, multicenter trial challenged this practice by comparing mitral repair with restrictive annuloplasty with valve replacement for IMR. The repair group had significant increase in recurrence rate of moderate or greater IMR at 2 years $(59 \%$ vs $4 \%))^{9}$ The most common mechanism underlying recurrence of IMR was persistence of leaflet tethering, which is not addressed with ring annuloplasty. LV remodeling after chronic ischemic events is an important factor in IMR.

The authors target this clinical need with an experimental device that reduces IMR and progression to heart failure. They created a unique device tailored to patient-specific LV and MV remodeling requirements. It is adjustable to achieve appropriate reverse remodeling in an infarcted and distorted LV. Although this 8-week recovery animal model does not replicate the chronic IMR remodeling of the LV seen clinically, the concept and application are intriguing, as surgical repair for correction of IMR has significant limitations. The development of external LV support device directed to the location of myocardial injury is a unique and innovative addition to the surgical armamentarium.

\section{References}

1. Kataoka A, Zeng X, Guerrero JL, Kozak A, Braithwaite G, Levine RA, et al. Application of polymer-mesh device to remodel left ventricular-mitral valve apparatus in ischemic mitral regurgitation. J Thorac Cardiovasc Surg. 2018;155: 1485-93. 
2. Batista RJ, Verde J, Nery P, Bocchino L, Takeshita N, Bhayana JN, et al. Partial left ventriculectomy to treat end-stage heart disease. Ann Thorac Surg. 1997;64:634-8.

3. Mann DL, Kubo SH, Sabbah HN, Starling RC, Jessup M, Oh JK, et al. Beneficial effects of the CorCap cardiac support device: five-year results from the Acorn Trial. J Thorac Cardiovasc Surg. 2012;143:1036-42.

4. Costanzo MR, Ivanhoe RJ, Kao A, Anand IS, Bank A, Boehmer J, et al. Prospective evaluation of elastic restraint to lessen the effects of heart failure (PEERLESSHF) trial. J Card Fail. 2012;18:446-58.

5. Menicanti L, Di Donato M, Frigiola A, Buckberg G, Santambrogio C, Ranucci M, et al. Ischemic mitral regurgitation: intraventricular papillary muscle imbrication without mitral ring during left ventricular restoration. J Thorac Cardiovasc Surg. 2002; $123: 1041-50$.
6. Messas E, Guerrero JL, Handschumacher MD, Conrad C, Chow CM, Sullivan S et al. Chordal cutting: a new therapeutic approach for ischemic mitral regurgitation. Circulation. 2001;104:1958-63.

7. Grigioni F, Enriquez-Sarano M, Zehr KJ, Bailey KR, Tajik AJ. Ischemic mitral regurgitation: long-term outcome and prognostic implications with quantitative Doppler assessment. Circulation. 2001;103:1759-64.

8. Beaudoin J, Levine RA, Guerrero JL, Yosefy C, Sullivan S, Abedat S, et al. Late repair of ischemic mitral regurgitation does not prevent left ventricular remodeling: importance of timing for beneficial repair. Circulation. 2013;128(11 suppl 1):S248-52.

9. Goldstein D, Moskowitz AJ, Gelijns AC, Ailawadi G, Parides MK, Perrault LP et al. Two-year outcomes of surgical treatment of severe ischemic mitral regurgitation. N Engl J Med. 2016;374:344-53. 